\title{
BMJ Open Insulin treatment of maternal diabetes mellitus and respiratory outcome in late-preterm and term singletons
}

\author{
Odile Becquet, ${ }^{1,2,3}$ Fares El Khabbaz, ${ }^{1,2,3}$ Corinne Alberti, ${ }^{3,4,5,6}$ \\ Damir Mohamed, ${ }^{4,5,6}$ Audrey Blachier, ${ }^{7}$ Valérie Biran, ${ }^{1,2,3}$ Olivier Sibony, ${ }^{1,2,3,8,9}$ \\ Olivier Baud ${ }^{1,2,3}$
}

To cite: Becquet $0, \mathrm{El}$ Khabbaz F, Alberti C, et al. Insulin treatment of maternal diabetes mellitus and respiratory outcome in latepreterm and term singletons BMJ Open 2015;5:e008192. doi:10.1136/bmjopen-2015008192

- Prepublication history for this paper is available online. To view these files please visit the journal online (http://dx.doi.org/10.1136/ bmjopen-2015-008192).

Received 14 March 2015 Revised 6 May 2015 Accepted 7 May 2015

CrossMark

For numbered affiliations see end of article.

Correspondence to Pr Olivier Baud; olivier.baud@rdb.aphp.fr

\section{ABSTRACT}

Objectives: While the incidence of diabetes mellitus (DM) during pregnancy has been steadily increasing in recent years, the link between gestational DM and respiratory outcome in neonates has not been definitely established. We asked the question whether DM status and its treatment during pregnancy could influence the risk of neonatal respiratory distress.

Design: We studied in a large retrospective cohort the relationship between maternal DM status (non-DM, insulin-treated DM (IT-DM) and non-insulin-treated DM (NIT-DM)), and respiratory distress in term and nearterm inborn singletons.

Results: Among 18095 singletons delivered at 34 weeks of gestation or later, $412(2.3 \%)$ were admitted to the neonatal intensive care unit (NICU) for respiratory distress within the first hours of life. The incidence of NICU admission due to respiratory distress groups was $2.2 \%, 5.7 \%$ and $2.1 \%$ in the nonDM, IT-DM and NIT-DM groups, respectively. Insulin treatment of DM, together with several other perinatal factors, was associated with a significant increased risk for respiratory distress. Several markers of the severity of respiratory illness, including durations of mechanical ventilation and supplemental oxygen, and hypertrophic cardiomyopathy were also found increased following IT-DM as compared with NIT-DM. In a multivariate model, we found that IT-DM, but not NIT-DM, was significantly associated with respiratory distress independent of gestational age and caesarean section, with an incidence rate ratio of 1.44 (1.00-2.08).

Conclusions: This study shows that the treatment of maternal DM with insulin during pregnancy is an independent risk factor for respiratory distress in term and near-term newborns.

\section{INTRODUCTION}

Respiratory morbidity in newborns at term ( $\geq 37$ weeks gestation) or near term (34-36 weeks gestation) is a concern that neonatologists and neonatal networks face daily. Among term newborns, about $1 \%$ are hospitalised for respiratory distress, mostly transient
Strengths and limitations of this study

- This study is the largest to explore the link between respiratory distress in late preterms and insulin treatment given to pregnant women.

- It provides new insights on insulin treatment regarding the severity of respiratory distress leading to neonatal intensive care unit admissions in a large cohort of inborn singletons.

- Owing to a retrospective study design, the degree of glycaemic control was not prospectively recorded in the database.

- This study does not allow one to distinguish between pregestational diabetes and gestational diabetes but is focused on insulin treatment.

tachypnoea of the newborn (TTN), and $0.2 \%$ need tracheal intubation and mechanical ventilation. ${ }^{12}$ Respiratory distress in late preterm newborns is even more frequent: more than $8 \%$ are hospitalised for respiratory distress related to either respiratory distress syndrome (RDS, $2 \%)$ or TTN $(6.5 \%){ }^{1}$ Since antenatal steroids are not currently recommended after 34 weeks of gestation, the improved identification of antenatal risk factors for respiratory distress in late preterm and term neonates could improve neonatal care.

Perinatal complications associated with diabetes mellitus (DM) during pregnancy are common and could lead to life-threatening morbidity in near-term infants. The incidence of DM during pregnancy has been estimated at $4-14 \%$ in the USA, and has been steadily increasing in recent years. ${ }^{3} 4$ This is related to the pandemic increase in obesity and type 2 DM in developed and lowincome countries. ${ }^{5}{ }^{6}$ The short-term effects of gestational DM are usually mild in the absence of pre-existing maternal DM, but can cause adverse pregnancy outcomes and neonatal complications. Despite a recent retrospective study showing an independent effect of gestational DM on the risk of 
respiratory distress in late preterm infants, ${ }^{7}$ the link between maternal DM during pregnancy and respiratory outcome in neonates has not been accurately established. In particular, the impact of insulin treatment needs to be clarified with regard to the respiratory status of the newborn. Indeed, the impact of maternal DM on fetuses and neonates, especially in terms of macrosomia and metabolic complications, varies widely depending on the nature of maternal DM and its treatment. ${ }^{8}$

This large retrospective cohort study was carried out to examine the relationship between maternal DM and respiratory distress in term and near-term inborn singletons, with a special focus on the impact of insulin used in difficult-to-control maternal DM.

\section{PATIENTS AND METHODS}

\section{Population studied}

This is a retrospective cohort study of all women followed at Robert Debré University Hospital (Paris, France) who gave birth to inborn singletons after 33 complete weeks of gestation between 1 January 2007 and 31 December 2013. Clinical, biological, maternal and neonatal data were prospectively reported in the perinatal database. Infants with congenital malformations or chromosomal aberrations were excluded from the analysis.

The 18095 live singleton neonates were split into two groups according to their respiratory status during the first hours of life:

- Neonates hospitalised for respiratory distress in the NICU of Robert Debré Hospital, a tertiary perinatal centre,

- Neonates without respiratory distress.

The retrospective review of our data clinical collection was approved by our institutional review board (IRB), the Comité de l'Evaluation de l'Ethique des Projets de Recherche Biomédicale de Robert Debré (CEERB-RD) $\mathrm{N}^{\circ}$ 2013-83. An information sheet was sent to parents for this retrospective study, but no written consent was required by the IRB.

\section{Diabetes status of the mothers}

DM screening during pregnancy was initially based on an O'Sullivan test, conducted between 24 and 28 weeks of gestation, and proposed to women with certain risk factors: age greater than 38 years, body mass index $>25 \mathrm{~kg} / \mathrm{m}^{2}$, a history of DM in first-degree relatives, a personal history of gestational DM or fetal macrosomia, excessive weight gain or fetal macrosomia during the current pregnancy. When the O'Sullivan test results were abnormal, an oral glucose load was proposed to confirm the diagnosis of gestational DM according to the WHO criteria.

Mothers were classified into three groups based on the presence or absence of DM and the type of DM treatment:

- Non-diabetic mothers (non-DM)

- Mothers with insulin-treated DM (IT-DM) in pregnancy. Insulin treatment was given according to standardised indications ${ }^{9}$
- Mothers with DM in pregnancy treated with diet alone, that is, non-insulin-treated DM (NIT-DM).

\section{Pregnancy-related and newborn-related variables}

Selected characteristics of the pregnancy and intrapartum period, including the main clinical events leading to each delivery, were recorded. Demographic, anthropometric, and clinical and biological data regarding maternal health and pregnancy were extracted from the maternity data register, which is systematically filled out for all women giving birth in our perinatal centre.

The duration of prolonged rupture of membranes was noted. A baseline fetal heart rate of less than $110 \mathrm{bpm}$ was considered abnormal.

The details of the infant's hospital course were recorded at discharge on a dedicated hospital chart. Respiratory outcomes were recorded at least every $3 \mathrm{~h}$ in the NICU. The first-line mode of mechanical ventilation used was usually synchronised intermittent mandatory ventilation. High-frequency oscillatory ventilation was restricted to the most serious cases of respiratory distress. The diagnoses of persistent pulmonary hypertension and hypertrophic cardiomyopathy were made on the basis of ultrasound findings by experienced physicians. The threshold of blood oxygenation at which the decision was made to administer supplemental oxygen was $<91 \%$. Oxygen therapy duration was calculated by summing mechanical ventilation duration and supplemental nasal oxygen therapy used after extubation. For variables measured in days, values of less than 1 day are indicated as 0.5 days.

\section{Statistical analysis}

Descriptive data are presented as medians (IQR (Q1-Q3)) for quantitative variables, and as number of patients (percentages) for qualitative variables. Comparisons of infants admitted to the NICU on the basis of maternal DM status (non-DM, IT-DM and NIT-DM) were performed using a $\chi^{2}$ test or Fisher's exact test, as appropriate, for qualitative variables, and a Kruskal-Wallis test for quantitative variables. The relationship between neonatal respiratory distress and DM status, adjusted for gestational age and maternal and infant characteristics, was studied using a Poisson regression. Data were checked for overdispersion, which was taken into account. Data were also verified for interactions between gestational age and DM status, and for the absence of collinearity of the included variables. Selection was carried out using a stepwise procedure with a threshold of entry of $20 \%$. Results are presented as incidence rate ratios (IRRs) with their 95\% CI (95\% CI).

Statistical analyses were performed with SAS V.9.3 software for PCs (SAS Institute, Cary, North Carolina, USA).

\section{RESULTS}

During the study period, 18095 singletons without congenital/chromosomal anomalies were delivered at 
34 weeks of gestation or later at the Robert Debré perinatal centre. Among them, 412 (2.3\%) were admitted to the NICU for respiratory distress within the first hours of life. The DM status of the mothers of the hospitalised infants, summarised in figure 1 , shows that $333(80.8 \%)$ were from non-DM mothers, $36(8.7 \%)$ from mothers with IT-DM, and 43 (10.4\%) from mothers with NIT-DM, treated with diet alone. The incidence of NICU admission due to respiratory distress among neonates from the different maternal DM groups was 2.2\%, $5.7 \%$ and $2.1 \%$ in the non-DM, IT-DM and NIT-DM groups, respectively.

The clinical characteristics of our cohorts of mothers and infants, according to the occurrence of respiratory distress, are shown in table 1.

The clinical characteristics of infants admitted to the NICU for respiratory distress, and of their mothers, depending on the DM status of the mother, are described in table 2.

No difference was noted due to maternal age, parity or gravidity. The only significant difference in antenatal variables was in the incidence of neonatal macrosomia above the 97th centile at birth, in particular in neonates born after a pregnancy complicated by IT-DM compared with the non-DM group ( $31 \%$ vs $6 \%, \mathrm{p}<0.0001)$. The gestational age at birth was also significantly different depending on the DM status of the mother: neonates born of mothers with IT-DM had a significantly lower gestational age at birth (37 weeks (35-39)) compared with either the NIT-DM group (39 weeks $(37-40)$ ) or the non-DM group (39 weeks (36-40); p=0.01). Similarly, birth weight was also found to be different between the three groups $(\mathrm{p}=0.004)$. The mode of delivery appeared to be related to the type of treatment of the DM during pregnancy. Children born to mothers with IT-DM were more likely to have been delivered by elective caesarean section than were neonates in the other two groups (IT-DM: 45\%; NIT-DM: 9\%; non-DM:
$15 \% ; \mathrm{p}=0.0002)$. In contrast, the rate of emergency caesarean section did not differ among the three groups (IT-DM: 22\%; NIT-DM: 28\%; non-DM: 24\%).

The median duration of hospitalisation was not statistically longer in infants born of mothers with IT-DM compared with the two other groups (4 vs 2 days, $\mathrm{p}=0.13$ ). Regarding the characteristics of respiratory distress (table 3), the IT-DM group displayed a trend in a longer duration of mechanical ventilatory support (3.2 vs $0.5-1$ day, $\mathrm{p}=0.07$ ) and oxygen therapy ( 3 vs $1-1.5$ day, $\mathrm{p}=0.07)$. There was a significant increase in the risk of hypertrophic cardiomyopathy following pregnancy complicated with IT-DM $(11 \%$ vs $0-2 \%, \mathrm{p}<0.0001)$. No difference was observed among the groups studied for other DM-related complications, type of ventilation or death.

In univariate analysis, the IRR in the studied cohort, adjusted for gestational age, revealed a significantly increased risk of respiratory distress when the pregnancy was complicated with IT-DM, but not NIT-DM, after caesarean section, and when one of the following factors was present: male gender, gestational hypertension or pre-eclampsia, HELLP syndrome, neonatal macrosomia above the 97th centile, meconium in the amniotic fluid, low APGAR scores/pH at birth, or intubation in the delivery room (table 4 ).

These factors can be considered to be risk factors for respiratory distress in neonates over 34 weeks, but were not influenced by the DM status of the mother (see table 2). Apart from intrapartum and postpartum factors tightly correlated with respiratory distress, the three highest risk factors for NICU admission in case of respiratory distress in our population were caesarean section during labour (IRR (95\% CI) 3.77 (2.96-4.80)), HELLP syndrome (IRR (95\%CI) $5.04(2.12-11.96)$ ) and IT-DM (IRR (95\%CI) 1.95 (1.35-2.81)).

In a multivariate model (see Methods section), we found that IT-DM, but not NIT-DM, was a risk factor

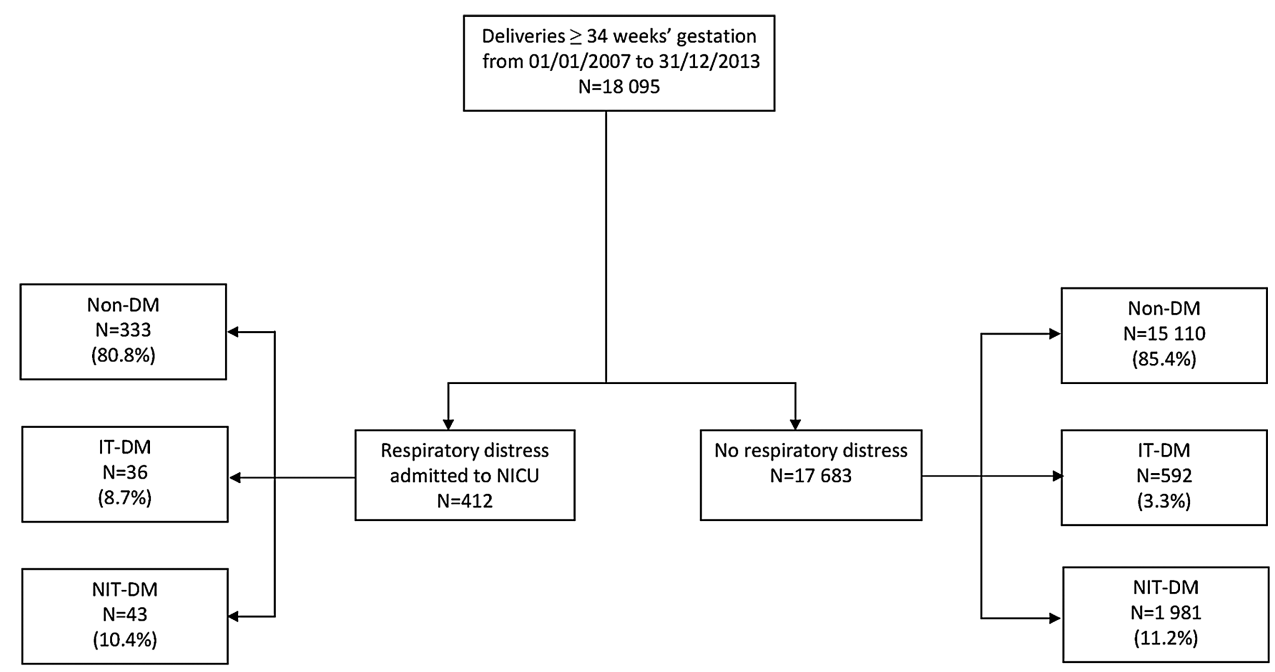

Figure 1 Participant flow in the cohort studied (NICU, neonatal intensive care unit; DM, diabetes mellitus; IT-DM, insulin-treated DM; NICU, neonatal intensive care unit; NIT-DM, non-insulin-treated DM). 
Table 1 Characteristics of the studied population

\begin{tabular}{|c|c|c|}
\hline Variable & $\begin{array}{l}\text { Respiratory distress } \\
\text { admitted to the NICU } \\
\mathrm{N}=412\end{array}$ & $\begin{array}{l}\text { No respiratory } \\
\text { distress } \\
N=17683\end{array}$ \\
\hline \multicolumn{3}{|l|}{$\overline{D M}$} \\
\hline Non-DM & $333(81 \%)$ & $15110(84 \%)$ \\
\hline IT-DM & $36(9 \%)$ & $592(3 \%)$ \\
\hline NIT-DM & $43(10 \%)$ & $1981(11 \%)$ \\
\hline \multicolumn{3}{|l|}{ Maternal age (years) } \\
\hline Median (Q1-Q3) & $31.3(27.5-35.7)$ & $31.3(27.5-35.2)$ \\
\hline \multicolumn{3}{|l|}{ Parity } \\
\hline Median (Q1-Q3) & $2(1-3)$ & $2(1-3)$ \\
\hline \multicolumn{3}{|l|}{ Gravidity } \\
\hline Median (Q1-Q3) & $2(1-4)$ & $2(1-4)$ \\
\hline \multicolumn{3}{|l|}{ Gestational age (weeks) } \\
\hline Median (Q1-Q3) & $39.0(36.0-40.0)$ & $38.0(37.0-40.0)$ \\
\hline \multicolumn{3}{|l|}{ Birth weight $(\mathrm{g})$} \\
\hline Median (Q1-Q3) & 3135 (2 570-3 600) & 3305 (3 000-3 625) \\
\hline Male & $238(58 \%)$ & $8938(50 \%)$ \\
\hline Gestational hypertension & $11(3 \%)$ & $192(1 \%)$ \\
\hline Pre-eclampsia & $23(6 \%)$ & $292(2 \%)$ \\
\hline HELLP syndrome & $6(2 \%)$ & $9(0 \%)$ \\
\hline Macrosomia >97th centile & $39(10 \%)$ & $1351(8 \%)$ \\
\hline Instrumental delivery & $85(21 \%)$ & 3708 (21\%) \\
\hline \multicolumn{3}{|l|}{ Delivery } \\
\hline Vaginal & $240(58 \%)$ & $14978(85 \%)$ \\
\hline Caesarean section during labour & $101(25 \%)$ & $1721(10 \%)$ \\
\hline Elective caesarean section & $71(17 \%)$ & $984(6 \%)$ \\
\hline Abnormal FHR before caesarean section & $104 / 172(61 \%)$ & 1 055/2 705 (39\%) \\
\hline \multicolumn{3}{|l|}{ Rupture of membranes duration $(\mathrm{h})$} \\
\hline Median (Q1-Q3) & $5(1-11)$ & $4(1-9)$ \\
\hline Meconium in amniotic fluid & $86(21 \%)$ & $1117(6 \%)$ \\
\hline \multicolumn{3}{|l|}{ APGAR scores (median (Q1-Q3)) } \\
\hline $1 \mathrm{~min}$ & $8(4-9)$ & $10(9-10)$ \\
\hline $5 \mathrm{~min}$ & $9(8-10)$ & $10(10-10)$ \\
\hline Intubation in delivery room & $114(28 \%)$ & $121(1 \%)$ \\
\hline $\mathrm{pH}$ at birth & $\mathrm{N}=404$ & $\mathrm{~N}=17099$ \\
\hline Median (Q1-Q3) & $7.3(7.2-7.3)$ & $7.3(7.3-7.4)$ \\
\hline
\end{tabular}

independent of gestational age and caesarean section, with an IRR of 1.44 (1.00-2.08) (table 5). No interaction between gestational age and type of DM was found.

\section{DISCUSSION}

Our study shows that the treatment of maternal DM with insulin during pregnancy is an independent risk factor for respiratory distress in term and near-term newborns.

Until now, the relationship between neonatal respiratory distress and the different types of maternal DM and their treatments was not clearly established. Our study confirms recent reports and presents new findings regarding DM treatment and its effect on the severity of respiratory distress leading to NICU admissions in a large cohort of inborn singletons.

The two main concerns in attempting to link DM and the respiratory status of the newborn at birth are interactions with prematurity and the route of delivery. Indeed, the incidence of prematurity in pregnancies with DM is known to be on the increase, ${ }^{10} 11$ especially in poorly controlled DM with frequent hyperglycaemic events. ${ }^{12}$ In our population, we found that neonates born to DM mothers treated with insulin were more likely to be premature than those born to non-DM or DM mothers treated with diet alone. Previous studies have reported that neonates born to DM mothers are more frequently delivered by caesarean section. ${ }^{13}$ We have refined this finding by showing a tight relationship between IT-DM and elective caesarean section to prevent maternal-fetal complications. On the other hand, the risk of respiratory distress in near-term and full-term infants has been found to be up to 3.9-fold higher when the birth occurs by caesarean section. ${ }^{14} 15$

Recently, two other studies have suggested that maternal DM is an independent risk factor for respiratory distress in neonates born after 34 weeks of gestation. ${ }^{7} 16$ However, the total number of infants with respiratory 
Table 2 Antenatal/perinatal characteristics of the studied population regarding DM treatment

\begin{tabular}{|c|c|c|c|c|}
\hline Variable & $\begin{array}{l}\text { Non-DM } \\
\mathrm{N}=333\end{array}$ & $\begin{array}{l}\text { IT-DM } \\
\mathrm{N}=36\end{array}$ & $\begin{array}{l}\text { NIT-DM } \\
\mathrm{N}=43\end{array}$ & p Value \\
\hline \multicolumn{5}{|l|}{ Maternal age (years) } \\
\hline Median (Q1-Q3) & $31.3(27.2-35.3)$ & $31.1(29.4-36.4)$ & $34.2(30.8-37.2)$ & 0.01 \\
\hline \multicolumn{5}{|l|}{ Parity } \\
\hline Median (Q1-Q3) & $2(1-3)$ & $2(1-4)$ & $2(1-2)$ & 0.13 \\
\hline \multicolumn{5}{|l|}{ Gravidity } \\
\hline Median (Q1-Q3) & $2(1-4)$ & $3(1-4)$ & $2(1-3)$ & 0.35 \\
\hline \multicolumn{5}{|l|}{ Gestational age (weeks) } \\
\hline Median (Q1-Q3) & $39(36-40)$ & 37 (35-39) & $39(37-40)$ & 0.01 \\
\hline \multicolumn{5}{|l|}{ Birth weight $(\mathrm{g})$} \\
\hline Median (Q1-Q3) & 3065 (2 550-3 530) & 3135 (2 565-3 615) & 3485 (3 065-3 990) & 0.004 \\
\hline Male & $190(57 \%)$ & $23(64 \%)$ & $25(58 \%)$ & 0.73 \\
\hline Gestational hypertension & $8(2 \%)$ & $2(6 \%)$ & $1(2 \%)$ & 0.33 \\
\hline Preeclampsia & $20(6 \%)$ & $2(6 \%)$ & $1(2 \%)$ & 0.74 \\
\hline HELLP syndrome & $4(1 \%)$ & $1(3 \%)$ & $1(2 \%)$ & 0.32 \\
\hline Macrosomia $>$ 97th centile & $20(6 \%)$ & $11(31 \%)$ & $8(19 \%)$ & $<0.0001$ \\
\hline Instrumental delivery & $69(21 \%)$ & $6(17 \%)$ & $10(23 \%)$ & 0.77 \\
\hline \multicolumn{5}{|l|}{ Rupture of membranes-duration (h) } \\
\hline median (Q1-Q3) & $4(1-11)$ & $1(0-9)$ & $6(2-15)$ & 0.18 \\
\hline \multicolumn{5}{|l|}{ Delivery } \\
\hline Vaginal & $201(60 \%)$ & $12(33 \%)$ & $27(63 \%)$ & 0.0002 \\
\hline Caesarean section during labour & $81(24 \%)$ & $8(22 \%)$ & $12(28 \%)$ & \\
\hline Elective caesarean section & $51(15 \%)$ & $16(45 \%)$ & $4(9 \%)$ & \\
\hline Abnormal FHR before caesarean section & $85(64 \%)$ & $10(24 \%)$ & $9(56 \%)$ & 0.10 \\
\hline Meconium in amniotic fluid & $71(21 \%)$ & $4(11 \%)$ & $11(26 \%)$ & 0.25 \\
\hline \multicolumn{5}{|l|}{ APGAR scores (median (Q1-Q3)) } \\
\hline $1 \mathrm{~min}$ & $8(4-9)$ & $7(4-9)$ & $7(4-9)$ & 0.51 \\
\hline $5 \min$ & $9(8-10)$ & $9(9-10)$ & $9(7-10)$ & 0.23 \\
\hline \multicolumn{5}{|l|}{$\mathrm{pH}$ at birth } \\
\hline median (Q1-Q3) & $7.3(7.2-7.3)$ & $7.3(7.2-7.3)$ & $7.3(7.2-7.3)$ & 0.08 \\
\hline
\end{tabular}


Table 3 Neonatal characteristics and complications observed in infants with respiratory distress regarding DM treatment

\begin{tabular}{|c|c|c|c|c|}
\hline Variable & $\begin{array}{l}\text { Non-DM } \\
\mathrm{N}=333\end{array}$ & $\begin{array}{l}\text { IT-DM } \\
\text { N=36 }\end{array}$ & $\begin{array}{l}\text { NIT-DM } \\
\mathrm{N}=43\end{array}$ & p Value \\
\hline \multicolumn{5}{|l|}{ Age at NICU admission (hours) } \\
\hline Median (Q1-Q3) & $0(0-0)$ & $0(0-0)$ & $0(0-0)$ & 0.43 \\
\hline Minimum; maximum & $0 ; 72$ & $0 ; 72$ & $0 ; 1$ & \\
\hline Exogenous surfactant & $20(6 \%)$ & $4(11 \%)$ & $6(14 \%)$ & 0.08 \\
\hline \multicolumn{5}{|l|}{ Number of surfactant doses instilled } \\
\hline 1 dose & $19 / 20(95 \%)$ & $3 / 4(75 \%)$ & $5 / 6(83 \%)$ & \\
\hline 2 doses & $1 / 20(5 \%)$ & $1 / 4(25 \%)$ & $1 / 6(17 \%)$ & \\
\hline Mechanical ventilation & $115(35 \%)$ & $13(36 \%)$ & $20(47 \%)$ & 0.31 \\
\hline \multicolumn{5}{|c|}{ Duration of mechanical ventilation (days) } \\
\hline Median (Q1-Q3) & $0.5(0.5-1.0)$ & $3.2(0.5-3.0)$ & $1.0(0.5-4.5)$ & 0.07 \\
\hline Minimum; maximum & $0.5 ; 8.0$ & $0.5 ; 18$ & $0.5 ; 7.0$ & \\
\hline Non-invasive ventilation & $175(53 \%)$ & $21(58 \%)$ & $23(55 \%)$ & 0.82 \\
\hline \multicolumn{5}{|c|}{ Duration of non-invasive ventilation (days) } \\
\hline Median (Q1-Q3) & $0.5(0.5-1.0)$ & $0.5(0.5-1.0)$ & $1.0(0.5-1.0)$ & 0.60 \\
\hline Minimum; maximum & $0.5 ; 7.0$ & $0.5 ; 4.0$ & $0.0 ; 4.0$ & \\
\hline Oxygen therapy & $57(17 \%)$ & $7(19 \%)$ & $4(10 \%)$ & 0.43 \\
\hline \multicolumn{5}{|l|}{ Duration of oxygen therapy (days) } \\
\hline Median (Q1-Q3) & $1.0(0.5-2.0)$ & $3.0(1.0-16.0)$ & $1.5(0.8-5.0)$ & 0.07 \\
\hline Minimum; maximum & $0.5 ; 15.0$ & $0.5 ; 18.0$ & $0.5 ; 8.0$ & \\
\hline Persistent pulmonaryhypertension & $9(3 \%)$ & $2(6 \%)$ & $3(7 \%)$ & 0.15 \\
\hline Hypertrophic cardiomyopathy & $1(0 \%)$ & $4(11 \%)$ & $1(2 \%)$ & $<0.0001$ \\
\hline Inotropes & $9(3 \%)$ & $2(6 \%)$ & $4(9 \%)$ & 0.05 \\
\hline Death & $4(1 \%)$ & $1(3 \%)$ & $1(2 \%)$ & 0.32 \\
\hline \multicolumn{5}{|l|}{ NICU stay duration (days) } \\
\hline Median (Q1-Q3) & $2.0(1.0-4.0)$ & $4.0(1.0-6.8)$ & $2.0(1.0-5.0)$ & 0.13 \\
\hline Minimum; maximum & $0.5 ; 37.0$ & $0.5 ; 57.0$ & $0.5 ; 13.0$ & \\
\hline
\end{tabular}

distress in the DM groups was quite low, and the type of DM treatment (diet or insulin) was not clearly specified.

The link between respiratory distress and IT-DM during pregnancy described in our study is consistent with a longer duration of mechanical ventilation and nasal oxygen therapy.

The limitations of our study are those inherent in all retrospective studies, even using computerised databases. The number of children with respiratory distress born of DM mothers is still small and does not allow us to draw any conclusions as to the characteristics of respiratory distress among the different types of maternal DM. Another limitation of our study is that the degree of glycaemic control was not prospectively recorded in the database.

Increased systemic glucose and serum insulin concentrations in the fetus are potential inhibitors of fetal lung maturation and may contribute to the pathogenesis of RDS in infants of DM mothers. ${ }^{17}$ In particular, insulin has been shown to inhibit the accumulation of mRNA for surfactant proteins (SPs) $\mathrm{A}$ and $\mathrm{B},{ }^{18}{ }^{19}$ although it has no effect on SP-C mRNA levels in human fetal lung tissue in vitro. ${ }^{20}$ However, there are conflicting reports in the literature as to the involvement of maternal hyperglycaemia in the delayed maturation of surfactants, ${ }^{21} 22$ and little support for a link between the occurrence of RDS and IT-DM during pregnancy. In preterm infants delivered before 33 weeks of gestation, Bental et $a l^{23}$ have reported that with adequate prenatal care, infants of DM mothers do not seem to be at an additional risk of developing RDS. Several factors could explain the variability of results reported between the study by Bental and the present study. First and most importantly, the gestational age group was different (very preterm vs late preterm). Second and consequently, the incidence of RDS was found to be much higher in Bental's study $(67-68 \%)$ than in our study (between $2 \%$ and $5 \%$ depending on the presence of DM in pregnancy). Third, the perinatal management of infants studied by Bental is much more operative (antenatal steroids, caesarean section, delivery room resuscitation). Finally, we have studied single pregnancies here. Altogether, these factors make the two studies not comparable. It is likely that in case of very preterm delivery, lung immaturity remains the first risk factor for RDS, irrespective of the presence or absence of DM in pregnancy.

Each type of DM seems to have a different implication for neonatal respiratory complications. Well-controlled maternal DM does not seem to increase the risk of neonatal respiratory distress. In contrast, pre-existing type 1 $\mathrm{DM}$, or severe maternal DM treated with insulin during pregnancy, appears to be responsible for increased respiratory morbidity independent of other risk factors, including caesarean section and prematurity. 
Table 4 Univariate analysis

\begin{tabular}{|c|c|c|}
\hline Variable & IRR (95\% CI) & p Value \\
\hline \multicolumn{3}{|l|}{$\mathrm{DM}$} \\
\hline Non-DM & 1 & \\
\hline IT-DM & 1.95 (1.35 to 2.81$)$ & 0.004 \\
\hline NIT-DM & $1.00(0.71$ to 1.39$)$ & 0.99 \\
\hline Maternal age (years) & 1.00 (0.99 to 1.02$)$ & 0.74 \\
\hline Parity & $0.92(0.85$ to 1.00$)$ & 0.06 \\
\hline Gravidity & 0.99 (0.93 to 1.05$)$ & 0.63 \\
\hline \multicolumn{3}{|l|}{ Delivery } \\
\hline Vaginal & 1 & \\
\hline Caesarean section during labour & 3.77 (2.96 to 4.80$)$ & $<0.0001$ \\
\hline Elective caesarean section & $2.96(2.24$ to 3.91$)$ & $<0.0001$ \\
\hline Birth weight $(\mathrm{g})$ & $1.00(1.00$ to 1.00$)$ & 0.76 \\
\hline \multicolumn{3}{|l|}{ Gender } \\
\hline Female & 1 & \\
\hline Male & $1.29(1.05$ to 1.58$)$ & 0.02 \\
\hline Gestational hypertension & $1.92(1.02$ to 3.62$)$ & 0.04 \\
\hline Pre-eclampsia & 1.70 (1.08 to 2.69$)$ & 0.02 \\
\hline HELLP syndrome & $5.04(2.12$ to 11.96$)$ & 0.0002 \\
\hline Macrosomia $>97$ th centile & $1.79(1.26$ to 2.54$)$ & 0.001 \\
\hline Instrumental delivery & $1.15(0.89$ to 1.48$)$ & 0.28 \\
\hline Premature rupture of membranes & $1.00(1.00$ to 1.00$)$ & 0.22 \\
\hline Meconium in amniotic fluid & $5.82(4.51$ to 7.52$)$ & $<0.0001$ \\
\hline APGAR score at $1 \mathrm{~min}$ & $0.67(0.66$ to 0.69$)$ & $<0.0001$ \\
\hline APGAR score at $5 \mathrm{~min}$ & $0.65(0.63$ to 0.67$)$ & $<0.0001$ \\
\hline $\mathrm{pH}$ at birth & $0.77(0.66$ to 0.89$)$ & 0.0007 \\
\hline Intubation in delivery room & 21.96 (17.74 to 27.18$)$ & $<0.0001$ \\
\hline
\end{tabular}

These observations suggest that insulin exposure may either be indicated by poorly controlled diabetes during pregnancy or make the mother less hyperglycaemic but with increased glycaemic instability leading to more fetal and neonatal complications. Whether insulin treatment or poorly controlled diabetes is related to neonatal complications remains unclear. Another crucial question is whether insulin treatment or pre-existing type 1 diabetes could be related to RDS. Among our IT-DM cohort, RDS was observed in $16 / 165$ neonates born from mothers with pre-existing

\begin{tabular}{|c|c|c|}
\hline Variable & IRR (95\% Cl) & p Value \\
\hline Gestational age & 0.70 (0.66 to 0.73$)$ & $<0.0001$ \\
\hline \multicolumn{3}{|l|}{ DM } \\
\hline Non-DM & 1 & \\
\hline IT-DM & 1.44 (1.00 to 2.08$)$ & 0.05 \\
\hline NIT-DM & 0.95 (0.68 to 1.32$)$ & 0.75 \\
\hline \multicolumn{3}{|l|}{ Delivery } \\
\hline Vaginal & 1 & \\
\hline $\begin{array}{l}\text { Caesarean section } \\
\text { during labour }\end{array}$ & 3.72 (2.92 to 4.74$)$ & $<0.0001$ \\
\hline $\begin{array}{l}\text { Elective caesarean } \\
\text { section }\end{array}$ & $2.81(2.11$ to 3.74$)$ & $<0.0001$ \\
\hline
\end{tabular}

DM, diabetes mellitus; IRR, incidence rate ratio adjusted for gestational age; IT-DM, insulin-treated DM; NIT-DM, non-insulin-treated DM. type $1 \mathrm{DM}$, and in 20/427 neonates born from mothers with type 2 IT-DM $(9.7 \%$ vs $4.7 \%, \mathrm{p}<0.05)$, suggesting that type $1 \mathrm{DM}$ may play a central role in the occurrence of RDS in late preterm.

Antenatal steroids are not currently recommended in preterm labour after 34 weeks of gestation. However, our study suggests that the benefits of antenatal steroids for lung maturation in case of IT-DM should be re-evaluated in a controlled study of this specific population.

\section{Author affiliations}

${ }^{1}$ Neonatal Intensive Care Unit, Université Paris Diderot, Sorbonne Paris Cité, Paris, France

${ }^{2}$ Assistance Publique-Hôpitaux de Paris, Hôpital Robert Debré, Paris, France

${ }^{3}$ PremUP Foundation, Paris, France

${ }^{4}$ Université Paris Diderot, Sorbonne Paris Cité, UMR-S 1123, ECEVE, Paris, France

${ }^{5}$ Unit of Clinical Epidemiology, Assistance Publique-Hôpitaux de Paris, Hôpital Robert Debré, Paris, France

${ }^{6}$ INSERM, U1123 and CIC-EC 1426, Paris, France

${ }^{7}$ Assistance Publique-Hôpitaux de Paris, Hôpital Robert Debré, Département d'information médicale, Paris, France

${ }^{8}$ Université Paris Diderot, Sorbonne Paris Cité, Paris, France

${ }^{9}$ Assistance Publique-Hôpitaux de Paris, Hôpital Robert Debré, Service de Gynécologie Obstétrique, Paris, France

Contributors $\mathrm{OB}$, FEK and $\mathrm{OB}$ designed the study and collected data. $\mathrm{CA}, \mathrm{DM}$ and $A B$ performed statistical analyses. $O B, V B, O S$ and $O B$ contributed to the discussion and wrote the paper.

Funding This research received no specific grant from any funding agency in the public, commercial or not-for-profit sectors. 
Competing interests None declared.

Ethics approval The retrospective review of our data clinical collection was approved by our institutional review board (IRB), the Comité de l'Evaluation de l'Ethique des Projets de Recherche Biomédicale de Robert Debré (CEERB-RD) N²013-83. An information sheet was sent to parents for this retrospective study, but no written consent was required by the IRB.

Provenance and peer review Not commissioned; externally peer reviewed.

Data sharing statement No additional data are available.

Open Access This is an Open Access article distributed in accordance with the Creative Commons Attribution Non Commercial (CC BY-NC 4.0) license, which permits others to distribute, remix, adapt, build upon this work noncommercially, and license their derivative works on different terms, provided the original work is properly cited and the use is non-commercial. See: http:// creativecommons.org/licenses/by-nc/4.0/

\section{REFERENCES}

1. Rubaltelli FF, Bonafe L, Tangucci M, et al. Epidemiology of neonatal acute respiratory disorders. A multicenter study on incidence and fatality rates of neonatal acute respiratory disorders according to gestational age, maternal age, pregnancy complications and type of delivery. Italian Group of Neonatal Pneumology. Biol Neonate 1998;74:7-15.

2. Gouyon JB, Ribakovsky C, Ferdynus C, et al., Burgundy Perinatal Network. Severe respiratory disorders in term neonates. Paediatr Perinat Epidemiol 2008;22:22-30.

3. Hedderson MM, Darbinian JA, Ferrara A. Disparities in the risk of gestational diabetes by race-ethnicity and country of birth. Paediatr Perinat Epidemiol 2010;24:441-8.

4. Yogev $\mathrm{Y}$, Visser GH. Obesity, gestational diabetes and pregnancy outcome. Semin Fetal Neonatal Med 2009;14:77-84.

5. Anna V, van der Ploeg HP, Cheung NW, et al. Sociodemographic correlates of the increasing trend in prevalence of gestational diabetes mellitus in a large population of women between 1995 and 2005. Diabetes Care 2008;31:2288-93.

6. Mitanchez D, Burguet A, Simeoni U. Infants born to mothers with gestational diabetes mellitus: mild neonatal effects, a long-term threat to global health. J Pediatr 2014;164:445-50.

7. Fung GP, Chan LM, Ho YC, et al. Does gestational diabetes mellitus affect respiratory outcome in late-preterm infants? Early Hum Dev 2014;90:527-30.
8. Jones CW. Gestational diabetes and its impact on the neonate. Neonatal Netw 2001;20:17-23.

9. Durnwald CP. Insulin analogues in the treatment of gestational diabetes mellitus. Clin Obstet Gynecol 2013;56:816-26.

10. Hedderson MM, Ferrara A, Sacks DA. Gestational diabetes mellitus and lesser degrees of pregnancy hyperglycemia: association with increased risk of spontaneous preterm birth. Obstet Gynecol 2003;102:850-6.

11. Yogev $Y$, Langer $O$. Spontaneous preterm delivery and gestational diabetes: the impact of glycemic control. Arch Gynecol Obstet 2007;276:361-5.

12. Ostlund I, Hanson U, Björklund A, et al. Maternal and fetal outcomes if gestational impaired glucose tolerance is not treated. Diabetes Care 2003;26:2107-11

13. Wahabi HA, Fayed AA, Alzeidan RA, et al. The independent effects of maternal obesity and gestational diabetes on the pregnancy outcomes. BMC Endocr Disord 2014;14:47.

14. Hansen AK, Wisborg K, Uldbjerg N, et al. Risk of respiratory morbidity in term infants delivered by elective caesarean section: cohort study. BMJ 2008;336:85-7.

15. De Luca $\mathrm{R}$, Boulvain $\mathrm{M}$, Irion $\mathrm{O}$, et al. Incidence of early neonatal mortality and morbidity after late-preterm and term cesarean delivery. Pediatrics 2009;123:e1064-71.

16. Vignoles P, Gire C, Mancini J, et al. Gestational diabetes: a strong independent risk factor for severe neonatal respiratory failure after 34 weeks. Arch Gynecol Obstet 2011;284:1099-104.

17. McGillick EV, Morrison JL, McMillen IC, et al. Intrafetal glucose infusion alters glucocorticoid signalling and reduces surfactant protein mRNA expression in the lung of the late gestation sheep fetus. Am J Physiol Regul Integr Comp Physiol 2014;307:R538-45

18. Miakotina OL, Goss KL, Snyder JM. Insulin utilizes the PI 3-kinase pathway to inhibit SP-A gene expression in lung epithelial cells. Respir Res 2002;3:27.

19. Miakotina OL, Dekowski SA, Snyder JM. Insulin inhibits surfactant protein $A$ and $B$ gene expression in the $\mathrm{H} 441$ cell line. Biochim Biophys Acta 1998;1442:60-70.

20. Dekowski SA, Snyder JM. The combined effects of insulin and cortisol on surfactant protein mRNA levels. Pediatr Res 1995;38:513-21.

21. Piper JM, Xenakis EM, Langer O. Delayed appearance of pulmonary maturation markers is associated with poor glucose control in diabetic pregnancies. J Matern Fetal Med 1998;7:148-53.

22. Moore TR. A comparison of amniotic fluid fetal pulmonary phospholipids in normal and diabetic pregnancy. Am J Obstet Gynecol 2002;186:641-50.

23. Bental $Y$, Reichman B, Shiff $Y$, et al. Impact of maternal diabetes mellitus on mortality and morbidity of preterm infants (24-33 weeks' gestation). Pediatrics 2011;128:e848-55. 